\title{
EVALUASI TATA KELOLA TEKNOLOGI INFORMASI DI PERPUSTAKAAN DAERAH KOTA SALATIGA DENGAN MENGGUNAKAN IT BALANCED SCORECARD
}

\author{
Vincent Sanjaya $^{1)}$, Andeka Rocky Tanaamah ${ }^{2)}$, dan Melkior Sitokdana ${ }^{3)}$ \\ ${ }^{1,2,3}$ Program Studi Sistem Informasi, Fakultas Teknologi Informasi, Universitas Kristen Satya Wacana \\ 1,2,3 J1. Diponegoro 52-60 Salatiga 50711, Indonesia \\ E-mail:682015100@student.uksw.edu ${ }^{1)}$, atanaamah@uksw.edu ${ }^{2)}$, melkior.sitokdana@uksw.edu ${ }^{3)}$
}

\begin{abstract}
ABSTRAK
Hampir semua organisasi telah memanfaatkan dan mengembangkan teknologi informasi dan sistem informasi untuk mendukung proses bisnisnya, baik organisasi profit maupun non-profit. Terutama organisasi Pemerintahan terus menggalahkan penerapan aplikasi Sistem Informasi untuk mewujudkan transparansi, akuntabilitas, efisiensi, dan efektifitas. Proses bisnis kepemerintahan dan layanan publik. Salah satu organisasi Pemerintahan yang langsung melayani publik adalah Perpustakaan Daerah Kota Salatiga. Tujuan dengan adanya penelitian ini adalah melakukan evaluasi kinerja Tata Kelola Teknologi Informasi Perpustakaan Daerah Kota Salatiga dan dapat memberikan manfaat bagi perpustakaan daerah seperti, dalam memberikan rekomendasi kepada manajemen pihak perpustakaan terhadap kinerja SI dan membantu mengoptimalkan sumber daya teknologi informasi. Penelitian ini menggunakan metode kualitatif, teknik pengumpulan data yang digunakan ialah wawancara dan observasi. Hasil dari penelitian di Perpustakaan Daerah Kota Salatiga mendapatkan hasil bahwa perspektif operational execellence dan business contribution telah berjalan dengan baik. Namun pada bagian user orientation mempunyai masalah yaitu buku dan e-book tidak tersedia, pada sistem SKD bermasalah pada jaringannya dan future orientation mempunyai masalah terhadap kapasitas bandwith. Dengan menggunakan IT balanced scorecard peneliti dapat dengan mudah mengklasifikasikan masalah yang ada di Perpustakaan Daerah Kota Salatiga.
\end{abstract}

Kata Kunci : Evaluasi Tata Kelola, Teknologi Informasi, IT Balanced Scorecard.

\section{PENDAHULUAN}

Perkembangan teknologi informasi dan komunikasi yang semakin canggih dan tersedia merupakan peluang dan sekaligus sebagai kekuatan untuk meningkatkan produktifitas kerja organisasi. Tanpa terkecuali semua organisasi telah memanfaatkan dan mengembangkan teknologi informasi dan sistem informasi untuk mendukung proses bisnisnya, baik organisasi profit maupun non-profit. Terutama organisasi Pemerintahan terus menggalahkan penerapan aplikasi Sistem Informasi untuk mewujudkan transparansi, akuntabilitas, efisiensi, dan efektifitas. Proses bisnis kepemerintahan dan layanan publik. Salah satu organisasi Pemerintahan yang langsung melayani publik adalah perpustakaan daerah Kota Salatiga.

Kebutuhan akan Sistem Informasi bagi organisasi, perusahaan, maupun lembaga instansi membuat perkembangan SI begitu pesat. Menggunakan SI adalah cara yang tepat untuk membuat sistem kerja dari suatu organisasi/perusahaan/lembaga instansi berkualitas didalam proses bisnis yang kompleks. Dalam penggunaan SI harus diimbangi dengan pengelolaan yang tepat. Karena penggunaan SI dikhawatirkan akan menimbulkan kerugian yang menimpa organisasi/perusahaan/lembaga instansi seperti, kehilangan data, penyalahgunaan komputer, informasi yang tidak akurat dan banyak lainnya. Evaluasi kinerja SI/TI sangat diperlukan guna menghindari kerugian-kerugian tersebut serta, menunjang performa kinerja agar lebih efisien dan efektif.

Berdasarkan observasi awal didapatkan hasil bahwa Perpustakaan daerah Kota Salatiga memiliki beberapa permasalahan yaitu, belum menerapkan manajemen resiko, belum optimalnya aplikasi pencarian buku secara online, kurang adanya Sumber Daya Manusia (SDM) dalam bidang SI / TI, belum melakukan audit SI / TI secara berkala, baik dari pihak internal maupun eksternal. Selain SI yang digunakan dalam Perpustakaan daerah kota Salati

perpustakaan juga memiliki website guna menunjang kinerja operasionalnya, website masih kurang aktif dan tidak dapat berfungsi sepenuhnya, seperti tidak dapat mengakses daftar buku yang terdapat di Perpustakaan daerah kota Salatiga, masih sangat minimnya e-book yang terdapat pada website tersebut, tampilan website Perpustakaan daerah kota Salatiga kurang menarik pembaca jika dibandingkan dengan website Perpustakaan Kabupaten Kudus. Oleh sebab itu dibuatlah penelitian ini dengan tujuan untuk mengevaluasi Tata Kelola Teknologi Informasi Perpustakaan Daerah Kota Salatiga dengan menggunakan IT Balance Score Card. Dengan IT Balanced akan melakukan evaluasi tata kelola SI/TI dengan mengkaji 4 perspektif yaitu, orientasi pengguna, kontribusi bisnis, keunggulan operasional, dan orientasi masa depan. 
Tujuan dengan adanya penelitian ini adalah melakukan evaluasi kinerja Tata Kelola Teknologi Informasi Perpustakaan Daerah Salatiga. Penelitian ini juga diharap memberikan manfaat bagi perpustakaan daerah, yaitu dalam memberikan rekomendasi kepada manajemen pihak perpustakaan terhadap kinerja SI dan membantu mengoptimalkan sumber daya teknologi informasi.

Penelitian yang dilakukan oleh Giska Sandra Legoh (2016) berjudul "Analisa Kinerja Sistem Informasi/Teknologi Informasi Pada BPPT \& PM Kota Salatiga Menggunakan Kerangka IT Balanced Scorecard" menjelaskan tentang pengukuran kinerja Sistem Informasi / Teknologi Informasi secara menyeluruh dilihat dari berbagai aspek untuk mendukung kinerja BPPT \& PM Kota Salatiga agar lebih efisien dan efektif. metode yang digunakan adalah IT Balanced Scorecard. Hasil yang diperoleh dalam penelitian ini adalah kinerja SI / TI cenderung baik dimana setiap perspektif memiliki nilainilai berikut, yaitu perspektif kontribusi organisasi adalah 1,4 , perspektif orientasi pengguna adalah 3 , perspektif keunggulan operasional adalah 3,3 dan orientasi perspektif masa depan 2,4.

Penelitian yang dilakukan oleh Murry Albert Agustin Lobo (2016) berjudul "Perencanaan Strategis Sistem Informasi Menggunakan IT Balanced Scorecard: studi kasus PT. Satya Mitra Sejahtera" menjelaskan tentang bagaimana membuat perencanaan strategis menggunakan IT Balanced Scorecard, dalam membuat perencanaan strategis system informasi PT.Satya Mitra Sejahtera dibuat berdasarkan 4 perspektif yang terdapat pada IT Balanced Scorecard. Hasil yang diperoleh dalam penelitian ini adalah perlu dirumuskan tujuan dan profil SI/TI seperti apa yang dibutuhkan perusahaan guna menjawab kebutuhan perusahaan dalam langkah mencapai tujuannya serta menghadapi tantangan kedepan. Penyusunan tujuan dan profil SI/TI organisasi harus mengacu pada visi dan misi dari PT. SMS agar implementasi SI/TI dalam organisasi dapat berjalan selaras dengan tujuan perusahaan. Kemudian perlu dilakukan analisis kesenjangan antara kondisi yang saat ini dengan kondisi yang diharapkan guna merumuskan solusi IT bagi perusahaan.

Penelitian yang dilakukan oleh Respati Ragil Pamungkas (2016) berjudul "Evaluasi Kinerja Sistem Informasi Produksi Perusahaan Manufaktur Menggunakan Metode IT Balanced Scorecard: Studi kasus PT. Anugrah Timbers, Salatiga" menjelaskan tentang cara untuk memanfaatkan IT agar dapat bersaing dengan perusahaan lainnya. Hasil yang diperoleh dalam penelitian ini adalah berdasarkan pengukuran yang dilakukan pada PT. Anugrah Timbers, Salatiga hasil yang didapat yaitu perspektif kontribusi organisasi sebesar $97.11 \%$, perspektif orientasi pengguna sebesar $85.02 \%$, perspektif keunggulan operasional sebesar $95.08 \%$ serta orientasi di masa depan sebesar $96.07 \%$.

Penelitian tedahulu menjelaskan tentang analisa, perencanaan, serta evaluasi suatu instansi dengan menggunakan kerangka IT Balanced Scorecard yang kemudian dijadikan dasar dan pedoman pada penelitian ini. Adapun perbedaan dari ketiga penelitian diatas ialah, pada penelitian pertama berfokus kepada kinerja SI/TI di suatu perusahaan, pada penelitian kedua berfokus kepada pembuatan perencanaan strategis SI yang baik untuk perusahaan dimasa depan, dan pada penelitian ketiga lebih berfokus kepada mengevaluasi kinerja SI disuatu perusahaan. Perbedaan dengan penelitian yang dilakukan ini tidak mengevaluasi atau menganalisa suatu perusahaan, melainkan lebih kepada suatu lembaga instansi Pemerintahan. Pada penelitian ini dengan judul "Evaluasi Tata Kelola Teknologi Informasi di Perpustakaan Daerah Kota Salatiga dengan menggunakan IT Balanced Scorecard" berfokus kepada mengevaluasi atau melihat secara keseluruhan tata kelola teknologi informasi di suatu instansi apakah berjalan dengan baik atau tidak, dan juga akan diberikan saran untuk instansi tersebut agar menjadi lebih baik lagi dimasa yang akan datang.

\section{RUANG LINGKUP}

Ruang lingkup penelitian ini adalah sebagai berikut;

1. Cakupan permasalahan dalam penelitian ini adalah kurangnya kinerja operasional dalam bidang SI/TI Perpustakaan Daerah Kota Salatiga yaitu belum menerapkan manajemen resiko, belum optimalnya aplikasi pencarian buku secara online, kurang adanya Sumber Daya Manusia (SDM) dalam bidang SI / TI, belum melakukan audit SI / TI secara berkala, baik dari pihak internal maupun eksternal.

2. Batasan penelitian ini hanya fokus pada sistem informasi yang dapat dievaluasi menggunakan IT Balance Scorecard.

3. Rencana hasil yang didapatkan dari penelitian ini adalah membantu instansi dalam mengevaluasi sistem informasi yang dimilikinya dan memberi rekomendasi kepada instansi tersebut.

\section{BAHAN DAN METODE}

Menurut Irwansyah dan Moniaga (2014), Teknologi Informasi (TI) adalah istilah umum untuk apapun yang membantu manusia dalam membuat, menyimpan, mengomunikasikan dan/atau menyebarkan informasi adalah TI. Teknologi Informasi merupakan sebuah studi perancangan, implementasi, pengembangan, dukungan atau manajemen sistem informasi berbasis komputer pada aplikasi perangkat keras atau hardware, perangkat lunak atau software, serta Infoware, Fireware, Brainware / User.

Sistem informasi adalah sistem di dalam suatu organisasi yang mempertemukan kebutuhan pengolahan transaksi harian, membantu dan mendukung kegiatan operasi, bersifat manajerial dari suatu organisasi dan membantu mempermudah penyediaan laporan yang diperlukan. Sistem informasi adalah data yang dikumpulkan, dikelompokan, dan diolah sedemikian rupa 
sehingga menjadi sebuah satu kesatuan informasi yang saling terkait (Manne \& Jane, 2013).

Tata kelola TI (IT Governance) adalah kapasitas organisasi sebagai tanggung jawab direksi, manajemen eksekutif, dan manajemen teknologi informasi untuk mengendalikan rumusan dan implementasi strategi SI/TI untuk memastikan selarasnya sumber daya SI/TI dengan bisnis organisasi (Van Grembergen, 2003). Grembergen menekankan pengertian tata kelola TI pada bagaimana organisasi memandang, mengelola dan mengoptimalkan sumber daya SI/TI yang dimilikinya.

Tata kelola TI adalah juga mengenai pengelolaan hak-hak dalam pengambilan keputusan dan kerangka kerja yang dapat dipertanggungjawabkan untuk mendorong terwujudnya hal-hal yang diharapkan dalam penggunaan SI/TI. Weill dan Ross mengusulkan lima pilar utama dari tata kelola TI yang perlu untuk dikelola oleh seluruh stakeholders organisasi. Kelima pilar tata kelola TI tersebut adalah IT Principles, IT architecture, IT Infrastructure, IT Business Application Needs, dan IT Investment (Weill \& Ross, 2004).

Pada tahun 1997, Van Grembergen dan Van Bruggen mengadopsi Balanced Scorecard (BSC) untuk digunakan pada Departemen Teknologi Informasi organisasi. Dalam pandangan mereka karena Departemen Teknologi Informasi merupakan penyedia layanan internal maka perspektif yang digunakan harus diubah dan disesuaikan. Dengan melihat bahwa pengguna mereka adalah pegawai internal dan kontribusi mereka dinilai berdasarkan pandangan pihak manajemen .

Konsep balanced scorecard dapat diterapkan pada fungsi TI dan dewan perusahaan (Van Grembergen, Saull, 2001). Dengan menggunakan balanced scorecard sampai batas maksimal, dapat memungkinkan manajemen TI dan dewan untuk mencapai tujuan mereka. IT Balanced Scorecard tidak hanya merupakan sistem manajemen kinerja, tetapi juga pada saat yang sama merupakan sistem manajemen ketika hubungan sebab akibat antara metrik sudah dilaksanakan sebagaimana mestinya (Kaplan \& Norton, 2000) .

Tabel 1. Perspektif dalam IT Balanced Scorecard( Van Grembergen dan Van Bruggen)

\begin{tabular}{|c|c|}
\hline $\begin{array}{l}\text { ORIENTASI } \\
\text { PENGGUNA }\end{array}$ & KONTRIBUSI BISNIS \\
\hline $\begin{array}{l}\text { Bagaimana pengguna } \\
\text { melihat departemen IT? } \\
\text { Tujuan: } \\
\text { Pemasok sistem informasi } \\
\text { yang disukai } \\
\text { Ukuran: } \\
\text { - Pemasok aplikasi yang } \\
\text { disukai } \\
\text { - Pemasok yang dipilih } \\
\text { dibandingkan dengan } \\
\text { pemberi solusi terbaik } \\
\text { - Kemitraan dengan } \\
\text { pengguna }\end{array}$ & $\begin{array}{l}\text { Bagaimana manajemen } \\
\text { memandang departemen } \\
\text { TI? } \\
\text { Tujuan: } \\
\text { Untuk mendapatkan } \\
\text { Kontribusi Bisnis yang } \\
\text { memiliki tujuan dari TI } \\
\text { Ukuran: } \\
\quad \text { - Mengontrol biaya TI } \\
\text { - Nilai bisnis dari proyek } \\
\quad \text { TI } \\
\text { Penyediaan kemampuan } \\
\text { bisnis yang baru }\end{array}$ \\
\hline
\end{tabular}

\begin{tabular}{|c|c|}
\hline Kepuasan pengguna & \\
\hline $\begin{array}{l}\text { KEUNGGULAN } \\
\text { OPERASIONAL }\end{array}$ & $\begin{array}{c}\text { ORIENTASI MASA } \\
\text { DEPAN }\end{array}$ \\
\hline $\begin{array}{l}\text { Seberapa efektif dan } \\
\text { efisiennya proses TI? } \\
\text { Tujuan: } \\
\text { Untuk memberikan } \\
\text { aplikasi dan layanan TI } \\
\text { yang efektif dan efisien } \\
\text { Ukuran: } \\
\text { - Perkembangan yang } \\
\text { efisien dan efektif } \\
\text { - Operasi yang efisien } \\
\text { dan efektif }\end{array}$ & $\begin{array}{l}\text { Seberapa efektif dan } \\
\text { efisiennya proses TI? } \\
\text { Tujuan: } \\
\text { Untuk mengembangkan } \\
\text { peluang dan untuk } \\
\text { menjawab tantangan masa } \\
\text { depan } \\
\text { Ukuran: } \\
\text { - Pelatihan dan } \\
\text { pendidikan staf TI } \\
\text { - Keahlian staf TI } \\
\text { - Penelitian teknologi } \\
\text { baru Umur dari portofolio } \\
\text { aplikasi }\end{array}$ \\
\hline
\end{tabular}

Penelitian ini menggunakan metode kualitatif yang bertujuan untuk memahami obyek yang diteliti secara mendalam, dengan memusatkan pada deskripsi data yang berupa kalimat-kalimat yang memiliki arti mendalam yang berasal dari informan dan perilaku yang diamati. Data hasil penelitian ini berupa fakta-fakta yang ditemukan pada saat di lapangan oleh peneliti (Sugiyono, 2016).

Teknik pengumpulan data yang digunakan ialah wawancara dan observasi. Penelitian ini dilakukan dengan menggunakan beberapa tahap, pertama dilakukan Identifikasi Masalah yang terjadi di Perpustakaan Daerah Kota Salatiga. Metode yang dilakukan adalah observasi selama 3 bulan, kemudian mempelajari literatur yang berhubungan IT Balanced Scorecard. Serta pengkajian tentang penelitian terdahulu yang relevan dan teori pendukung penelitian ini.

Dalam tahapan pengumpulan data, dilakukan kegiatan perolehan data dari auditee dengan menggunakan beberapa alat pengumpulan data, antara lain: wawancara dan observasi. Pengumpulan data wawancara dan observasi digunakan untuk memperoleh data mengenai profil Perpustakaan, profil bagian, kondisi sistem informasi yang diterapkan saat ini, dan berbagai temuan-temuan permasalahan yang muncul dengan kondisi sistem informasi yang diterapkan saat ini yaitu website perpustakaan.

Setelah melakukan pengumpulan data, maka tahapan selanjutnya adalah analisis data. Tahapan ini menjelaskan bagaimana menilai tingkat kematangan sistem informasi yang terdapat di Perpustakaan Daerah Kota Salatiga. Proses pertama dari analisis data ini yaitu memetakan visi misi Perpustakaan Daerah Kota Salatiga dengan tujuan teknologi informasi perpustakaan berdasarkan perspektif IT Balanced Scorecard untuk memperoleh keselarasan visi misi dan tujuan teknologi informasi (4 dimensi). Serta di buat table SWOT untuk membantu identifikasi kekuatan dan kelemahan Perpustakaan Daerah Kota Salatiga. SWOT sediri ialah analisa yang didasarkan pada logika yang dapat memaksimalkan kekuatan (strengths) dan peluang (opportunities), namun secara bersamaan 
dapat meminimalkan kelemahan (weaknesses) dan ancaman (threats) (Rangkuti, 2013).

\section{PEMBAHASAN}

Berdasarkan Peraturan Walikota Salatiga No. 38 Tahun 2016, Perpustakaan dan Kearsipan Kota Salatiga mempunyai tugas membantu Walikota melaksanakan urusan Pemerintahan yang menjadi kewenangan Daerah bidang Perpustakaan dan Kearsipan serta tugas pembantuan yang diberikan kepada Daerah. Adapun fungsi Dinas Perpustakaan dan Kearsipan Kota Salatiga sebagai perumusan kebijakan, pelaksanaan kebijakan, pelaksanaan evaluasi dan pelaporan, pelaksanaan administrasi dinas dan pelaksanaan fungsi lain yang diberikan oleh Walikota terkait dengan tugas dan fungsinya.

Pengevaluasian tata kelola teknologi informasi dengan menggunakan IT Balanced Scorecard pada Perpustakaan daerah Kota Salatiga yang bertujuan memberikan rekomendasi kepada pihak perpustakaan terhadap kinerja SI dan membantu mengoptimalkan sumber daya teknologi informasi. Dilakukan wawancara dan observasi untuk mengetahui permasalahan dalam Perpustakaan daerah Kota Salatiga dengan Kepala Perpustakaan Daerah Kota Salatiga yang diwakilkan dengan sekretarisnya.

Hasil wawancara dan observasi dibuat kedalam tabel SWOT untuk mengindentifikasi kekuatan dan kelemahan Perpustakaan Daerah Kota Salatiga, lalu hasil strategi dari analisis SWOT akan dibuat kedalam strategy map agar lebih memudahkan dalam melihat peluang yang ada untuk menjadikannya kekuatan dan meminimalisir kelemahan atau ancaman bagi Perpustakaan daerah Kota Salatiga.

Adapun Matriks SWOT pada tabel 2 untuk menjelaskan Kekuatan (Strength), Kelemahan (Weakness), Peluang (Opportunities), dan Ancaman (Threats) pada Sistem Informasi di Perpustakaan daerah Kota Salatiga.

\section{Tabel 2. Matriks SWOT}

\begin{tabular}{|c|c|c|}
\hline & $\begin{array}{l}\text { Kekuatan } \\
\text { (Strength) } \\
\text { Memiliki } \\
\text { aplikasi yang } \\
\text { mendukung } \\
\text { sistem informasi }\end{array}$ & $\begin{array}{l}\text { Kelemahan } \\
\text { (Weakness) } \\
\text { - Beberapa aplikasi } \\
\text { sering terjadi } \\
\text { masalah } \\
\text { Tidak memiliki } \\
\text { karyawan SI/TI yang } \\
\text { tetap }\end{array}$ \\
\hline $\begin{array}{l}\text { Peluang } \\
\text { (Opportunities) } \\
\text { - Setiap tahun } \\
\text { ada } \\
\text { pengembangan } \\
\text { dibidang SI/TI } \\
\text { Ketersediaan } \\
\text { SI/TI }\end{array}$ & $\begin{array}{l}\text { STRATEGI SO } \\
\text { - Mengembang } \\
\text { kan aplikasi } \\
\text { yang dimiliki } \\
\text { menjadi lebih } \\
\text { baik,efisien, } \\
\text { dan efektif }\end{array}$ & $\begin{array}{l}\text { STRATEGI WO } \\
-\quad \text { Meningkatkan } \\
\text { perbaikan pada } \\
\text { aplikasi yang } \\
\text { memiliki kendala } \\
\text { - Perekrutan pegawai } \\
\text { SI/TI yang tetap } \\
-\quad \\
\text { Menambah/pengemb } \\
\text { angan aplikasi SI/TI }\end{array}$ \\
\hline
\end{tabular}

\begin{tabular}{|l|l|l|}
\hline $\begin{array}{l}\text { Ancaman } \\
\text { (Threats) }\end{array}$ & STRATEGI ST & STRATEGI WT \\
- Tidak memiliki & $\begin{array}{l}\text { - Mempromosi } \\
\text { kan layanan }\end{array}$ & $\begin{array}{l}\text { - Memberikan } \\
\text { layanan fasilitas }\end{array}$ \\
pengunjung. & - Meningkatkan & yang baik \\
- Saingan dengan & fasilitas dan & Memastikan \\
perpustakaan & pelayanan & kepuasan pengunjung \\
swasta & pada aplikasi & dan kesejahtraan \\
Perpustakaan & & karyawan terjamin \\
banyak tersedia & & \\
secara online & & \\
\hline
\end{tabular}

Penjelasan Tabel Matriks SWOT pada tabel 2:

1. Strength Opportunities (SO): Dilihat dari kekuatan dan peluang, perpustakaan memiliki kekuatan yaitu memiliki aplikasi yang mendukung sistem informasi dan peluang yang berupa, Setiap tahun ada pengembangan dibidang SI/TI serta Ketersediaan SI/TI sehingga Strategi SO adalah untuk mengembangkan aplikasi yang dimiliki menjadi lebih baik,efisien, dan efektif.

2.Strength Threats (ST): Dilihat dari kekuatan dan ancaman, perpustakaan memiliki kekuatan yaitu memiliki aplikasi yang mendukung sistem informasi dan ancaman yang berupa tidak memiliki pengunjung, saingan dengan perpustakaan swasta, serta perpustakaan yang banyak tersedia secara online untuk mengatasi hal tersebut maka dibuatlah Strategi ST berupa meningkatkan fasilitas dan pelayanan pada aplikasi.

3. Weakness Opportunities (WO): Dilihat dari kelemahan dan peluang, perpustakaan memiliki kelemahan berupa; beberapa aplikasi memiliki kendala, tidak memiliki karyawan SI/TI yang tetap, namun perpustakaan memiliki peluang yang berupa, Setiap tahun ada pengembangan dibidang SI/TI serta Ketersediaan SI/TI sehingga Strategi WO ialah meningkatkan perbaikan pada aplikasi yang memiliki kendala, perekrutan pegawai SI/TI yang tetap, dan menambah/pengembangan aplikasi SI.

4. Weakness Threats (WT): Dilihat dari kelemahan dan ancaman, perpustakaan memiliki kelemahan berupa; beberapa aplikasi memiliki kendala, tidak memiliki karyawan SI/TI yang tetap, serta ancaman yang berupa tidak memiliki pengunjung, saingan dengan perpustakaan swasta, dan perpustakaan yang banyak tersedia secara online, maka Strategi WT untuk menghindari hal tersebut ialah memberikan layanan fasilitas yang baik dan memastikan kepuasan pengunjung.

Kemudian dari hasil penjelasan strategi diatas dibuatlah peta strategi (Strategy Map) dari keempat persperktif IT Balanced Scorecard agar lebih memudahkan proses identifikasi, menganalisa peluang agar lebih memudahkan dalam melihat peluang yang ada untuk menjadikannya kekuatan dan meminimalisir kelemahan atau ancaman bagi Perpustakaan daerah Kota Salatiga. 


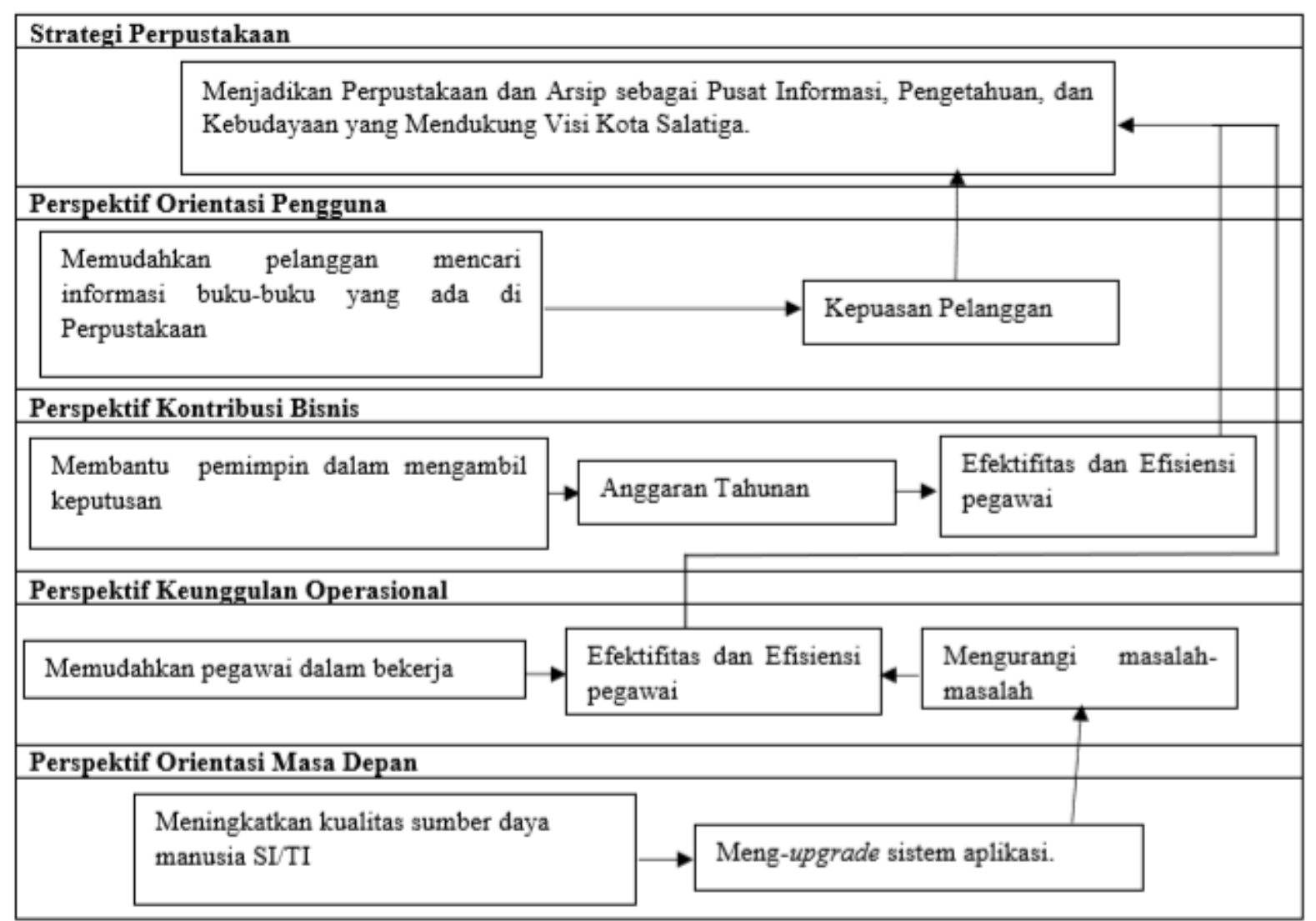

Gambar 1. Strategy Map

Keempat perspektif IT Balanced Scorecard dirancangkan untuk mendukung visi dan misi dari Perpustakaan Daerah Kota Salatiga.

1. Dari Perspektif Orientasi Pengguna setelah pelanggan dimudahkan dalam mencari buku-buku dan informasi mengenai Perpustakaan Daerah Kota Salatiga, angka tingkat kepuasan pelanggan akan meningkat dan menunjang visi dan misi Perpustakaan Daerah Kota Salatiga.

2. Perspektif Kontribusi Bisnis menjelaskan bahwa Pemimpin atau Pimpinan Perpustakaan Daerah Kota Salatiga sangat terbantu dalam pengambilan keputusan karena, Pimpinan jadi mengetahui berapa buku yang banyak dipinjam dan buku apa saja yang digemari oleh pelanggan untuk pembelian buku selanjutnya. Hal ini tentunya sangat berkaitan dengan anggaran Perpustakaan Daerah Kota Salatiga. Selain itu anggaran juga dimanfaatkan untuk investasi SI/TI yang menunjang efektifitas dan efisiensi karyawan. Hal ini juga dapat meningkatkan kepuasan pelanggan.

3. Pada Perspektif Keunggulan Operasional dapat dilihat bahwa Sistem aplikasi di Perpustakaan Daerah Kota Salatiga sangat membantu karyawannya dalam menjalankan pekerjaan, proses ini sangat membantu dalam efektifitas dan efisiensi karyawan. Walaupun ada beberapa masalah pada sistem, namun kendala-kendala tersebut diatasi oleh pegawai dengan cepat guna menunjang performa kinerja Perpustakaan Daerah Kota Salatiga.

4. Dari permasalahan yang ada dapat dijadikan bahan evaluasi di masa mendatang, oleh sebab itu perspektif Masa depan menjelaskan bahwa, Perpustakaan Daerah Kota Salatiga memiliki misi kedepan untuk lebih meningkatkan performa kinerja baik Sumber Daya Manusianya maupun Sistem aplikasinya. Yang memiliki tujuan untuk mengurangi permasalahan permasalahan yang ada dan mendukung visi misi awal dari Perpustakaan Daerah Kota Salatiga.

Setelah perumusan Strategy Map, dirumuskanlah penjabaran dari keempat perspektif IT Balanced Scorecard sebagai berikut:

\subsection{Operational Excellence}

Dalam Perpustakaan Daerah Kota Salatiga kota Salatiga memiliki beberapa sistem informasi diantaranya Sistem Kearsipan Dinamis (SKD), Slims (Senayan Library Management System), Isalatiga (Aplikasi ebook), Sistem Arsip Pribadi (SIAP), Sistem Kearsipan Kuno (SIKANO). SKD adalah Sistem yang dipakai pada seluruh OPD di Salatiga untuk sistem surat masuk dan surat keluar. Surat yang diterima atau akan dikeluarkan di scan kemudian di upload kedalam SKD. Untuk Slims merupakan aplikasi open source untuk sistem perpustakaan peminjaman dan pengembalian. Untuk Isalatiga aplikasi untuk android dimana buku-buku yang tersedia didalamnya dibeli oleh perpustakaan daerah 
salatiga untuk dijadikan ebook dan bisa dibaca dimasyarakat luas, sistem aplikasi yang digunakan dikembangkan oleh pihak ketiga dengan adanya MOU selama 5 tahun. Untuk SIAP sistem yang digunakan oleh bidang kearsipan untuk masyarakat salatiga. Namun dalam implementasinya sering terjadi masalah seperti yang diungkapkan oleh Ibu Andis, selaku Staf Sekretariat Perpustakaan daerah Kota Salatiga.

Dari sistem informasi yang dimiliki memiliki manfaat yaitu sudah sangat bagus untuk memudahkan pengguna, misalnya SKD admin pusat aplikasi berada di perpustakaan daerah salatiga, namun setiap OPD memiliki admin masing-masing untuk memudahkan sistem mепији e-government. Dan iSalatiga untuk memudahkan baca online. Walaupun memiliki manfaat sistem informasi dari Perpustakaan Daerah Kota Salatiga namun memiliki kendala yang dirasakan oleh pegawai dari Perpustakaan Daerah Kota Salatiga yaitu dalam aplikasi SKD server yang dimiliki oleh SKD kurang besar, karena dipakai oleh seluruh OPD kota salatiga dan adanya kendala di database. Kendala-kendala tersebut diatasi oleh pegawai dengan cepat serta harus ditinjau kembali secara detail masalahnya, karena harus melakukan penganggaran dan semua perbaikan masalah tergantung anggarannya.

\subsection{User Orientation}

Dari sisi user orientation memberikan fasilitas untuk memudahkan pelanggan Perpustakaan Daerah Kota Salatiga dalam mencari informasi buku-buku yang ada di Perpustakaan dan juga mengunggah atau mengunduh file yang dimiliki oleh pelanggan, untuk mengetahui status peminjaman dan pengembalian buku serta sistem informasi yang digunakan gratis. Penggunaan sistem informasi terhadap pelanggan disurvei selama satu tahun sekali dan semua data kepuasan pelanggan tercatat dalam IKM (Indeks Kepuasan Masyarakat). Dari hasil survei salah satu keluhan yang ditemukan oleh Perpustakaan Daerah Kota Salatiga yaitu buku dan e-book tidak tersedia, pada sistem SKD jaringannya karena servernya kecil.

Berdasarkan temuan diatas didapatkan bahwa pada sisi user orientation memiliki kekurangan yaitu buku dan e-book tidak tersedia, pada sistem SKD jaringannya karena servernya kecil. Sehingga seharusnya Perpustakaan Daerah Kota Salatiga lebih sering memperbaharui sistem yang ada sehingga buku-buku dan e-book dapat tersedia serta memperbesar server agar tidak mengalami kendala pada kapasitas penyimpanan.

\subsection{Future Orientation}

Pada Future Orientation atau Orientasi pada masa depan, bertujuan untuk mengembangkan peluang dan untuk menjawab tantangan dimasa depan, serta mengetahui seberapa efektif dan efisien proses TI. Kepuasan pegawai Perpustakaan Daerah Kota Salatiga dalam penggunaan sistem informasi Cukup puas, hanya namun terkadang kendala internet karena hanya bandwith 100 Mbps dengan manajemen sistem pembagiannya.
Sehingga Perpustakaan Daerah Kota Salatiga mempunyai rencana pengembangan sistem informasi untuk kedepannya yaitu Setiap tahun dilakukan pengembangan.

SKD jadi ke android SLIMS pada bulan agustus mendatang akan di upgrade menjadi aplikasi yang lebih canggih dari Perpusnas. Jika ingin menambahkan sistem informasi pihak Perpustakaan Daerah Kota Salatiga segera merapatkan dan menentukan pihak ketiga yang akan melakukan proyek tersebut. Sedangkan dalam upaya meningkatkan kualitas sumber daya manusia SI/TI Perpustakaan Daerah Kota salatiga mengikuti program Peralatan Komputer (PRAKOM) yang dibuat oleh Badan Kepegawaian, Pendidikan dan Pelatihan Daerah.

Berdasarkan temuan diatas didapatkan bahwa pada sisi future orientation memiliki kekurangan yaitu pada sistem manajemen pembagian jaringan internet dengan hanya memiliki bandwith 100 Mbps.. Seharusnya Perpustakaan Daerah Kota Salatiga harus memiliki manajemen pembagian yang jelas dengan memperbesar bandwith internet baik pada bagian kantor Perpustakaan dan bagian untuk pelanggan.

\subsection{Business Contribution}

Perpustakaan Daerah Kota Salatiga mempunyai anggaran investasi SI/TI yang dilakukan satu tahun sekali, lalu pada tahun 2020 anggaran SI/TI akan terpusat di Kominfo. Manfaat yang didapatkan dari investasi SI/TI cukup besar, dilihat dari keuntungan-keuntungan, angka IKM, pertambahan pengunjung. Membuat perpustakaan lebih menarik. Untuk presentase penggunaan SI dalam meningkatkan produktivitas kerja bagi karyawan sudah 90\% menggunakan sistem. Dalam sistem juga membantu pemimpin dalam mengambil keputusan untuk mengetahui berapa buku yang banyak dipinjam dan buku apa saja yang digemari oleh pelanggan.

Dari hasil dan pembahasan dari keempat perspektif IT Balanced Scorecard diatas dirangkumkan rekomendasi sebagai berikut:

Tabel 3. Tabel Rekomendasi

\begin{tabular}{|c|c|c|}
\hline DIMENSI & MASALAH & REKOMENDASI \\
\hline $\begin{array}{l}\text { Operational } \\
\text { Excellence }\end{array}$ & $\begin{array}{l}\text { Tidak ada } \\
\text { masalah dari sisi } \\
\text { sitem } \\
\text { informasinya, } \\
\text { Perpustakaan } \\
\text { memiliki } \\
\text { aplikasi dan } \\
\text { sistem informasi } \\
\text { yang bermanfaat } \\
\text { untuk } \\
\text { memudahkan } \\
\text { pengguna. }\end{array}$ & $\begin{array}{l}\text { Sistem Informasi } \\
\text { yang sudah sangat } \\
\text { baik harus } \\
\text { dipertahankan dan } \\
\text { terus dikembangkan } \\
\text { agar menjadi lebih } \\
\text { baik. }\end{array}$ \\
\hline $\begin{array}{l}\text { User } \\
\text { Orientation }\end{array}$ & $\begin{array}{l}\text { - Buku dan e- } \\
\text { book tidak } \\
\text { tersedia. } \\
\text { Pada sistem } \\
\text { SKD } \\
\text { bermasalah pada } \\
\text { jaringannya, }\end{array}$ & $\begin{array}{l}\text { - } \text { Perpustakaan } \\
\text { Daerah Kota } \\
\text { Salatiga harus } \\
\text { lebih sering } \\
\text { memperbaharui } \\
\text { sistem yang ada } \\
\text { sehingga buku- }\end{array}$ \\
\hline
\end{tabular}




\begin{tabular}{|c|c|c|}
\hline & $\begin{array}{l}\text { karena } \\
\text { servernya kecil. }\end{array}$ & $\begin{array}{l}\text { buku dan e-book } \\
\text { dapat tersedia . } \\
\text { Memperbesar server } \\
\text { agar tidak } \\
\text { mengalami kendala } \\
\text { pada kapasitas } \\
\text { penyimpanan }\end{array}$ \\
\hline $\begin{array}{l}\text { Future } \\
\text { Orientation }\end{array}$ & $\begin{array}{l}\text { Sistem } \\
\text { manajemen } \\
\text { pembagian } \\
\text { jaringan internet } \\
\text { dengan hanya } \\
\text { memiliki } \\
\text { bandwith } 100 \\
\text { Mbps. }\end{array}$ & $\begin{array}{l}\text { Seharusnya } \\
\text { Perpustakaan Daerah } \\
\text { Kota Salatiga harus } \\
\text { memiliki manajemen } \\
\text { pembagian yang } \\
\text { jelas dengan } \\
\text { memperbesar } \\
\text { bandwith internet } \\
\text { baik pada bagian } \\
\text { kantor Perpustakaan } \\
\text { dan bagian untuk } \\
\text { pelanggan. }\end{array}$ \\
\hline $\begin{array}{l}\text { Business } \\
\text { Contribution }\end{array}$ & $\begin{array}{l}\text { Tidak ada } \\
\text { masalah, pada } \\
\text { perspektif bisnis } \\
\text { konstribusi, baik } \\
\text { dalam anggaran, } \\
\text { presentase } \\
\text { produktivitas } \\
\text { karyawan, } \\
\text { maupun dalam } \\
\text { pengambilan } \\
\text { keputusan sudah } \\
\text { baik. }\end{array}$ & $\begin{array}{l}\text { Sistem Informasi } \\
\text { yang sudah sangat } \\
\text { baik harus } \\
\text { dipertahankan dan } \\
\text { terus dikembangkan } \\
\text { agar menjadi lebih } \\
\text { baik. }\end{array}$ \\
\hline
\end{tabular}

\section{KESIMPULAN}

Hasil dari penelitian di Perpustakaan Daerah Kota Salatiga mendapatkan hasil bahwa aspek operational execellence dan business contribution telah berjalan dengan baik dan sangat memudahkan dari pihak pimpinan, pegawai, maupun pelanggan karena telah dilakukannya survei sekali dalam satu tahun. Namun pada bagian user orientation dan future orientation masih mengalami kendala pada server dan keterbatasan bandwith. Dengan menggunakan IT balanced scorecard peneliti dapat dengan mudah mengklasifikasikan masalah yang ada di Perpustakaan Daerah Kota Salatiga.

\section{SARAN}

Untuk penelitian selanjutnya, diharapkan lebih dalam lagi mengkaji tetang aplikasi yang digunakan oleh Perpustakaan Daerah Kota Salatiga serta dapat membantu menyelesaikan masalahnya. Akan sangat bermanfaat bagi Perpustakaan Daerah Kota Salatiga untuk memiliki programmer tetap. Selain itu, temuan peneliti pada awal observasi sangatlah berbeda dengan hasil yang didapatkan, yaitu bahwa Perpustakaan Daerah Kota Salatiga masih sangat membutuhkan pengembangan dalam website dan aplikasi pencarian buku otomatis karena dari hasil yang didapat, Perpustakaan Daerah Kota Salatiga sudah memiliki aplikasi, namun pengetahuan masyarakat masih kurang. Oleh karena itu, Perpustakaan Daerah Kota Salatiga perlu meningkatkan promosi atau sosialisasi agar masyarakat semakin mengetahui perkembangan Perpustakaan Daerah Kota Salatiga dan layanan yang diberikan.

\section{DAFTAR PUSTAKA}

Irwansyah,E dan Moniaga,V.J. 2014. Pengantar Teknologi Informasi.ed.1.Yogyakarta: deepublish

Jr, Raymond McLeod, 1997. Sistem Informasi Manajemen Versi Bahasa Indonesia. Prenhallindo, Jakarta.

Kaplan, R and Norton, D. 2000. The Balanced Scorecard: Measures That Drive Performance. Harvard Business School Publishing. Massachusetts, United States of America.

Legoh, G. 2016. Analisa Kinerja Sistem Informasi/Teknologi Informasi pada BPPT \& PM Kota Salatiga Menggunakan Kerangka IT Balanced Scorecard. Program Studi Sistem Informasi FTIUKSW

Lobo, M. 2016. Perencanaan Strategis Sistem Informasi Menggunakan IT Balanced Scorecard: studi kasus PT. Satya Mitra Sejahtera. Program Studi Sistem Informasi FTI-UKSW

Pamungkas, R. 2016. Evaluasi Kinerja Sistem Informasi Produksi Perusahaan Manufaktur Menggunakan Metode IT Balanced Scorecard: studi kasus PT. Anugrah Timbers, Salatiga. Salatiga: Fakultas Teknologi Informasi Uksw

Pertiwi, A. 2011. Balanced Scorecard Sebagai Alat Pengukur Kinerja Perguruan Tinggi (IT Telkom). Institut Teknologi Telkom

Purnomo, E. 2002. Sistem Analisis. Andi Offset. Yogyakarta

Rangkuti, F. 2013. Analisis SWOT Teknik Membedah Kasus Bisnis. Gramedia Pustaka Utama. Jakarta. hal.19

Sugiyono. 2016. Metode Penelitian Kuantitatif, Kualitatif, dan $R \& D$. PT Alfabet; Bandung

Van Grembergen, W and Van Bruggen, R. 1997. Measuring and Improving Corporate Information Technology Through The Balanced Scorecard Technique. Wim Van Grembergen. The Netherlands.

Van Grembergen, W and Saull, R. 2001. Aligning Business and Information Technology through the Balanced Scorecard at a Major Canadian Financial Group: its Status Measured with an IT BSC Maturity Model. Proceedings of the 34th Hawaii International Conference on System Sciences.

Van Grembergen, W. 2003. Strategies for information Technology Governance. IGI Publishing Hershey, PA, USA.

Weill, P.,and Ross, J. 2004. IT Governance: How top performers manage IT decision rights for superior results. Boston : Harvard business school press.

Wenno \& Jane,J. 2013. Perancangan Sistem Informasi Penggajian Berbasis Web (Studi Kasus Kantor Walikota Ambon). Salatiga: Fakultas Teknologi Informasi Uksw. 